\title{
Experimental Analysis of the Physical Degradation of Polymers - The Case of Polymethyl Methacrylate
}

\author{
Kaddouri Afaf*, Serier Boualem, Kaddouri Khacem, Belhouari Mohamed \\ University of Djillali Liabes, Laboratory of Mechanics Physics of Materials (LMPM Laboratory), Sidi Bel Abbes, Algeria. \\ Kaddouri.af@gmail.com,serielem@yahoo.fr,kaddourikacem@yahoo.fr,belhouar@yahoo.com
}

\begin{abstract}
Polymers are known to be sensitive to aging; their lifetime can be predicted through experimental tests.

This paper displays an experimental study on the long-term performance of polymethyl methacrylate (PMMA) exposed to solar (UV) radiations and artificial (UV) lamp radiations, drinking water and sea water. The performance of this polymer was analyzed in terms of strain variation; strain at break in tension, and Young's modulus. The results obtained showed that the amount of absorbed water is independent of the nature of the solvent, and only the absorption kinetics may be regulated by the species contained in the medium. This seems to indicate that plastification of polymers is a reversible phenomenon. In addition, it was found that the tensile strength and elastic modulus drop with increasing immersion time. Compared with seawater, the absorption of drinking tap water, after 36 months, leads to a non-linear behavior of the polymethyl methacrylate. Exposition of PMMA to artificial (UV) lamp radiations and solar (UV) radiations, for the same duration of exposure, resulted in greater performance degradation when the polymer was exposed to artificial (UV) lamp radiations. In addition, the results obtained after a 19 month exposure period that the artificial (UV) lamp radiations changes the behavior of this material from viscoelastic to viscoplastic.
\end{abstract}

KEYwORDS. Polymethyl methacrylate; Aging; Artificial (UV) lamp radiations and solar (UV) radiations; Sea water; Drinking water; Mass gain.

\section{OPEN ACCESS}

Citation: Afaf, K., Serier, B., Kaddouri, K. Belhouari, M., Experimental Analysis of the Physical Degradation of Polymers - The Case of Polymethyl Methacrylate, Frattura ed Integrità Strutturale, 53 (2020) 66-80.

Received: 08.01 .2020

Accepted: 06.05.2020 Published: 01.07.2020

Copyright: (C) 2020 This is an open access article under the terms of the CC-BY 4.0, which permits unrestricted use, distribution, and reproduction in any medium, provided the original author and source are credited.

\section{INTRODUCTION}

$\mathrm{P}$ olymers offer remarkable technological solutions in many fields; they belong to a class of materials that are increasingly used in industries ranging from consumer goods to aerospace products, including healthcare items. Polymer matrix nano-composites are widely employed materials as many researchers predict that they are entitled to a bright future and can be a solution to the more and more severe commissioning conditions. Nowadays, these materials can seriously compete with traditional ones, like mineral materials, because of their low density; also, their thermomechanical properties are becoming more and more elaborate (functional polymers). Furthermore, these materials 
have become attractive because they are recyclable, especially thermoplastics, and present excellent corrosion resistance. Because of the attractive mechanical properties of polymethyl methacrylate (PMMA) and its ability to be easily shaped, many research studies have focused on this polymer to improve its service strength. Indeed, PMMA can be used in nanotechnology, particularly in electronics, medicine, civil engineering, mechanical engineering, telecommunications (fiber optics), marine engineering, aeronautics, aerospace, consumer goods industries, etc. [1-7]. Nevertheless, it has been shown that the exposure of this polymer to heat, sun radiation, humidity and some solvents may lead to the degradation of its mechanical properties. Several research studies have been conducted on the aging behavior of polymethyl methacrylate when exposed to these media. Indeed, while Bokoi et al. [8] studied the cracking behavior of hydrated and stressed PMMA, they found out that the water absorption process can help to determine the mode of crack propagation. Dry PMMA has excellent scratch resistance; it is often deposited on substrates as a coating to improve this resistance. For this purpose, Moghbelli et al. [9] showed that water affects this resistance. In addition, in this same study, depending on the polarity and time of exposure, they showed that the presence of water acts as a harmless lubricator on the surface of the polymer, which can prevent the formation of scratches. After a period of 22 days of PMMA in water heated to $60{ }^{\circ} \mathrm{C}$, Shen et al. [10] concluded that for a1\% absorption content, this solvent leads to the plasticization of the polymer. For higher amounts of water, the polymer loses its transparency and significant changes occur during the deformations.

The aging resistance of PMMA can also be affected by other environmental media, including light, gamma radiation and heat. In this context, Miller et al. [11] investigated the effects of ultraviolet (UV) light, temperature, and moisture on aging PMMA materials using an aging test bench supplied with xenon lamps; they also compared the outdoor exposure test results for the purpose of predicting the service life of these materials. For their part, Fu et al. [12], by analyzing the effect of temperature on the physical aging of high molecular weight PMMA, showed that the aging process results in a decrease in the coefficient of permeability and an increase in selectivity. They also suggested that a modified three-parameter fit model can help predict the long-term physical aging behavior. These findings are in good agreement with the experiment results. On the other hand, Cheng et al. [13] investigated the effect of thermal aging on the scratch resistance of PMMA subjected to a normal progressive load; they reached the conclusion that a longer aging time can lead to a decrease in the critical load for triggering superficial cracks, which means that crack resistance of PMMA drops with longer aging time. Thominette and Verdu [14] studied the case of PMMA subjected to tensile stress and gamma radiation; they could show that either one of the two mechanisms could lead to a splitting of the primary macro-radical; this mechanism could be activated by the constraint. Similarly, Wenhua Yin et al. [7] investigated the aging behavior of PMMA in a liquid scintillator, at different temperatures and subjected to static tensile forces; they found out that an increase in the aging temperature engenders a rapid drop in the tensile strength of the PMMA. In another study, Karollyne Gomes de Castro Monsores et al. [15] reported that the ultraviolet (UV) radiation can modify the rigidity of PMMA, and causes a drop in its elongation at break and its tensile strength.

On the other hand, Mambaye N'Diaye et al. [16] showed that PMMA used as orthopedic cement in contact with the body fluids can swell after 24 hours if placed in distilled water. Similarly, in order to improve the photovoltaic performance of PMMA, Myles P. et al. [17] exposed two types of polymethyl methacrylate to high intensity ultraviolet (UV) radiation and also to a concentrated xenon arc. These authors indicated that, compared to the xenon arc, exposure of this material to UV radiations leads to an increase in PMMA photo-degradation that is three to six times higher. In addition, E. Youssif et al. [18] reported that when the polymer is exposed to UV radiation, photo-degradation is the main cause of deterioration of aging resistance. For their part, A. Ghasemi-kahrizsangi et al. [19] indicated that, depending on the nature of the polymer, exposure to UV radiation can lead to degradation of the surface of the material due mainly to the removal of the surface layers and also to the formation of pitting and microcracks. Similarly, F. Namouchia et al. [20] studied the effect of thermal aging on the electrical properties of polymethyl methacrylate (PMMA) and found out that such aging promotes the phenomenon of oxidation of the polymer and can therefore cause an increase in the number of free radicals. This can lead to the polarization of the PMMA and may give it a less insulating character. As for O.D. Gonzales et al. [21], they deduced that the optical stress coefficient of PMMA subjected to tensile stresses varies according to the water content. On the other hand, Y. Minhyuk et al. [22] examined the effect of physical aging on the thermomechanical properties of PS-PMMA through the measurement of silicon microcantilever deflections; they found out that these polymers interact during the glass transition. Similarly, T. Šaraca et al. [23] investigated the effect of simultaneous aging, due to heat treatment and gamma irradiation, on the mechanical and physico-chemical properties of the industrial ethylene-propylenediene monomer (EPDM). They suggested that the mechanical properties of this monomer, and in particular the ultimate tensile stress and elongation at break, are highly dependent on the radiation dose rate, the aging temperature and dose rate. Furthermore, Alenka Vesel Opens et al. [24] investigated the effect of oxygen plasma treatment on the aging of polymethyl methacrylate (PMMA). In this case, the samples were aged in dry air and water at ambient temperature. A study of the effect of this type of treatment on the quality of the PMMA / elastomer junction was conducted by Suzhu Yu 
et al. [25] who highlighted the beneficial effect of this treatment not only on the mechanical strength of the PMMAelastomer interface but also on the degradation of its properties due to aging. For their part, Jing Zhao et al. [26] tried to elucidate, by the suspension polymerization process, how can microcapsules for thermal energy storage compensate for damage caused by ultraviolet (UV) light. These same authors demonstrated the beneficial impact of these microcapsules on the PMMA lifetime. Indeed, they found out that these microcapsules have a high thermal storage capacity, good reliability and thermal stability, and provide good protection against UV radiations. As for Merdas et al. [27], they investigated the effect of the polymer polarity on the absorption of water. They succeeded in showing that the absorption of water increases with the polarity of the polymer; this absorption is more significant for interpenetrating polymer networks than for individual network components, and does not generally depend on the large-scale network structure. With regard to Ángel Serrano-Aroca et al. [28], they carried out a dynamic mechanical analysis and investigated the sorption of water vapor in highly porous poly(methyl methacrylate) (PMMA). They were able to show that sorption increases with the crosslinking agent of the cross-linker as a result of the higher number of polar COO groups; however, it decreases with increasing porosity due to the formation of water clusters, which prevents water molecules from occupying all the specific surface of the highly porous polymer. On the other hand, it has been revealed that freshwater sorption increases considerably in very porous PMMA. Research team of David Miller et al. [29] reported that seawater has an impact on the behavior and performance of the vinylester epoxy composite and leads to decreased tensile strength, compression and fatigue. Moreover, Ryota Imaizumi et al. [30] investigated the resistance of poly (N-methylmaleimide-altisobutene) and poly (disopropyl fumarate), as transparent polymer films, to UV and gamma radiations; they successfully demonstrated that UV irradiation leads to the cleavage of the PMI and PDiPF side chain via the Norrish I-type reaction and also due to the cross-linking resulting from the combination of radicals of the polymers formed, which leads to degradation of their optical and mechanical properties. Indeed, it has been found that radiation induces significant changes in the mass of molecules and in the mechanical properties of polymers as well. Similarly, S.I. Senatova et al. [31] examined the effect of UV radiation on the structure and properties of PP nanocomposites. These same researchers argued that the most prevailing mechanism involved in the protection of PP composites is the absorption of UV radiations by zinc oxide $(\mathrm{ZnO})$ nanoparticles. Reducing the UV radiation intensity prevents the breakage of molecular chains within polypropylene (PP) and its oxidation. These nanoparticles may be recommended to protect polymers against UV radiation. In another study, T. Lu et al. [32, 33, 34] and G. Wypych [35] showed through an experimental study that long-term exposure of polymers to high UV radiation levels leads to faster degradation of their aging resistance. In addition, their immersion in water produces the same effects. Xavier Monnier [36] studied Molecular dynamics in complex polymer systems: from anisotropy to confinement effects. It is shown that high cooling rates available by FSC allow to accelerate physical aging kinetics. It is shown that preferential orientation induced during electrospinning leads to the formation of mesophase, wich increase cooperativity, namely the intermolecular interactions. Yamina Hanafi [37] showed through her study the degradation of polyethersulfone / polyvinylpyrrolidone membranes by sodium hypochlorite that the PES-chain scission mechanism appeared to play the major role in the worsening of the membrane filtration performance. Under the ageing conditions of this study it seems that neither the PES hydroxylation nor the PVP degradation play a significant role in the worsening of the membrane rejection properties. Finally, the membrane structure was found to be substantially altered by the action of sodium hypochlorite, especially for membranes containing PVP. NADIM AHMED HASEG [38] have studied the molecular mobility of poly(methyl methacrylate) (PMMA) during a physical ageing, at various temperatures. This study was carried out by means of two techniques, namely i) mechanical spectroscopy (MS) with scanning in temperature for 4 nearly simultaneous frequencies $0.33 \mathrm{~Hz}$ and $20 \mathrm{~Hz}$, and ii) differential scanning calorimetry (DSC). Concerning the experimental aspect, this study has allowed to find the two well known relaxation processes $\alpha$ and $\mathrm{b}$ and to highlight an additional signal induced by preliminary aging procedure. This peak due to structural relaxation strongly depends on the preliminary condition of annealing (temperature and time aging) and appears to be nearly non frequency dependent, as assesses by mechanical spectroscopy. Géraldine Rapp [39] studied a thermal aging of polyethylene used as cable insulation, shows that: The oxidation kinetics obey the Arrhenius law for thermal ageing between $80^{\circ} \mathrm{C}$ and $110^{\circ} \mathrm{C}$. The variations of mechanical properties can be linked to the evolution of the microstructure of each polymer and of their macromolecular architecture during thermo-oxidative ageing.

The polymer (PMMA) is a material that is predominantly used in industrial devices operating in cumulative immersion environments such as seawater, drinking water (tap water) and is generally exposed to ultraviolet (UV) and solar radiations.

The main purpose of this study is to highlight by experimental analysis the effect of these environmental media on the long-term performance of the polymer (PMMA), in terms of the tensile strength variations, strain at rupture variation and Young's modulus variation. 


\section{EXPERIMENTAL ANALYSIS}

$\mathrm{T}$

he mechanical properties of the polymethyl methacrylate (PMMA), of chemical formula $\left(\mathrm{C}_{5} \mathrm{O}_{2} \mathrm{H}_{8}\right) \mathrm{n}$, are given in Tab. 1. This is an amorphous transparent thermoplastic hard and rigid but fragile and notch-sensitive material. It is mainly used in an industrial device, namely the photobioreactor, which consists of two transparent PMMA plates, assembled in a PVC frame (Fig. 1). This device, containing seawater, is exposed simultaneously to natural lighting (solar (UV) radiations) and artificial lighting (artificial (UV) lamp radiations). The designer and user of this device are both especially interested in its long-term behavior, under the operating conditions mentioned above. Then, the service life of this device, which consists of these two plates, immersed in water for 36 months and exposed to solar (UV) and artificial (UV) lamp radiations also for a length of 36 months, was examined in the long term. In order to be in the conditions of use of this device, PMMA tensile specimens were prepared (Fig. 2) by molding, then at room temperature $\left(20^{\circ} \mathrm{C}\right.$ ) immersed separately in seawater and drinking water (tap water). They were then exposed to the solar (UV) radiations and artificial (UV) lamp radiations. These specimens were tested in uniaxial tension with a transverse displacement speed of $0.5 \mathrm{~mm} / \mathrm{min}$.

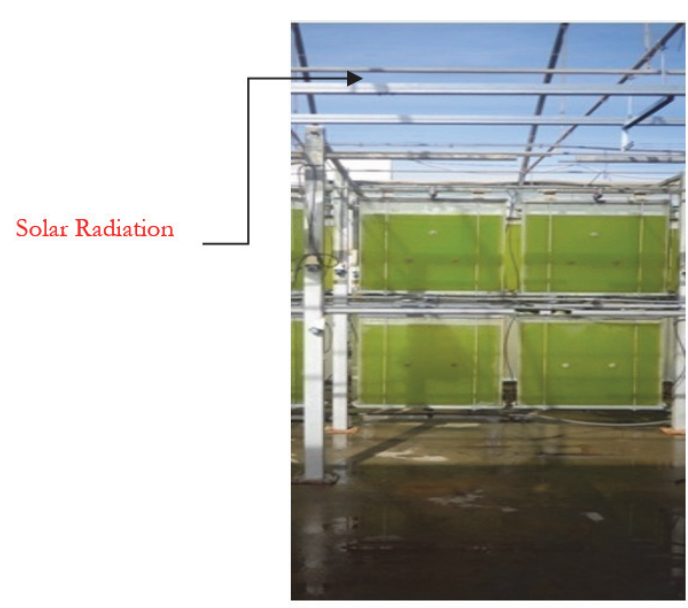

a) Production device

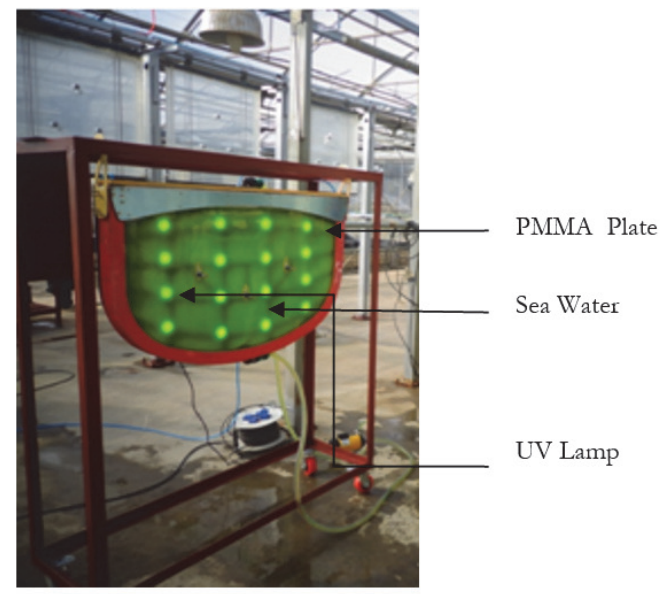

b) Prototype

Figure 1: Photobioreactor made with PMMA.

\begin{tabular}{cc}
\hline Modulus of elasticity $(\mathrm{MPa})$ & $3200-4000$ \\
Poisson's ratio & $0.35-0.40$ \\
Stress at rupture (break) $(\mathrm{MPa})$ & $70-80$ \\
Strain at rupture (break) $(\%)$ & 2.4 \\
\hline
\end{tabular}

Table 1: Mechanical properties of PMMA as given by the supplier.

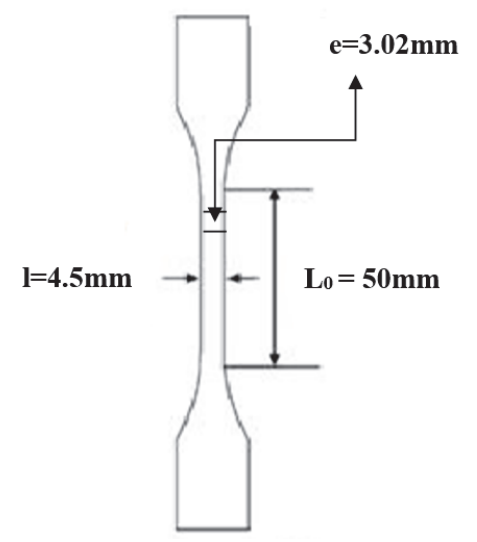

Figure 2: Tensile specimen made with PMMA: ISO 527-2. 
Tests were carried out on a recent software-driven Zwick machine with $25 \mathrm{KN}$ resistance, equipped with a camera and a chamber that are required for the good conduct of the tests, at different temperatures (Fig. 3). This machine is perfectly suited for polymer materials. For the reproducibility of the results, these tests were performed on a batch of six (6) samples non-aged and under various aging conditions. Again, the tensile test was performed on a batch of six samples, and the average value was selected, as shown in Fig. 4. After immersion in water brought to room temperature $\left(20^{\circ} \mathrm{C}\right)$, the samples were dried with compressed air.

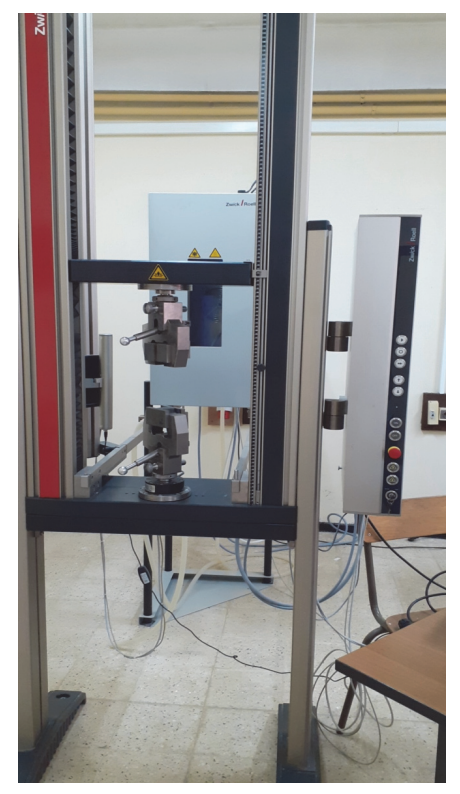

Figure 3: Tensile testing machine.

\section{RESULTS AND DISCUSSION}

7 o better understand the effects of aging, unaged (dry) PMMA samples (six samples) were weighed with a very high precision scale (up to $10^{-6} \mathrm{~g}$ ) and were then tested for uniaxial tension, as shown in Fig. 4 which clearly exhibits the linear and brittle behavior of PMMA. The average values of the modulus of elasticity (3750 MPa), tensile strength $(69 \mathrm{MPa})$ and strain at break $(2.31 \%)$ determined from this figure are comparable to those obtained by other authors [22].

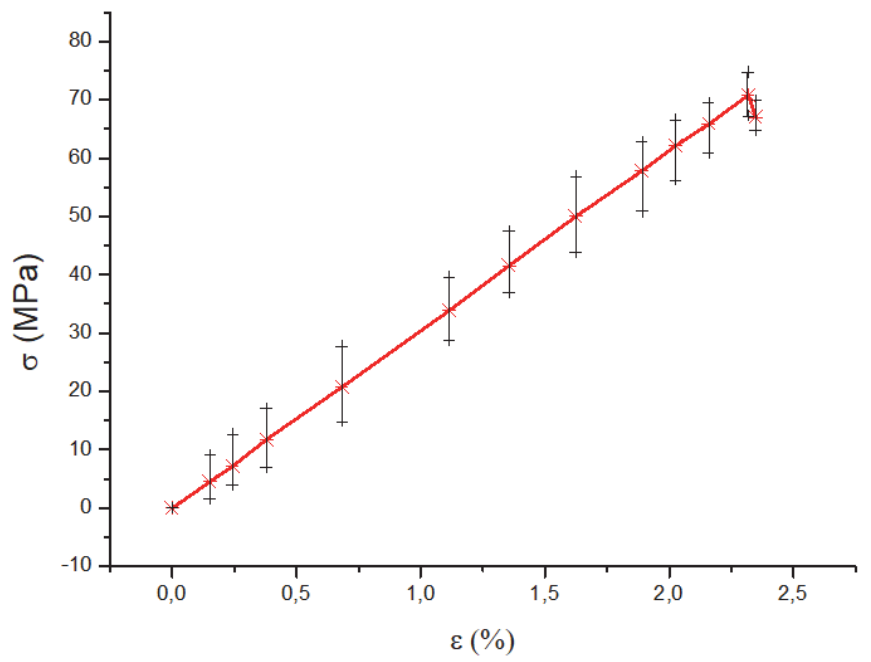

Figure 4: Variation of stress as a function of strain for unaged dry polymethyl methacrylate (PMMA) 


\section{IMMERSION IN WATER}

ensile specimens were immersed separately, at room temperature and atmospheric pressure, in drinking water (tap water) and in seawater, for a period ranging from one to thirty-six months; they were than dried with compressed air and weighed and then tested in uniaxial tension. The absorption of water by PMMA during aging was determined in terms of the mass gain rate, $\Delta M / M$ as a function of the square root of the immersion time " $\mathrm{t}^{1 / 2}$ " (fig. 5). It has been shown that the penetration of water to the PMMA obeys to the Fick's low and in this case the depth of water flow is proportional to " $\mathrm{t}^{1 / 2}$ ". Fig. 5 shows explicitly during the first months, immersion in drinking water (tap water) leads to the absorption of an amount of water (Fig. 5a) larger than that in seawater (Fig. 5b). Thus, after a cumulative aging of eight months, the amount of absorbed water was found approximately twice as high $(1.25 \%)$ in drinking water as in seawater $(0.70 \%)$.

After a 19-month immersion period in drinking water (tap water) and in seawater, separately, the maximum percentages of absorbed water were $1.58 \%$ and $1.51 \%$, respectively. These proportions correspond to the saturation levels in water molecules absorbed by the polymer. The amount of water absorbed by the PMMA seems to be insensitive to the immersion time, as can be seen in Fig. 5 (a, b). A close examination of this figure clearly shows that the diffusion kinetics of seawater in PMMA is much slower than that of drinking water (tap water) in the same polymer. Indeed, the speed of water molecules is higher during the first moments of immersion, and then begins to slow down to reach its lowest level after 19 months of aging (Fig. 5a). In seawater, as compared to drinking water (tap water), during the first five months of immersion, the speed of water molecules is relatively slow; it then begins to increase and stabilizes after a cumulative aging of 36 months (Fig. 5b). This behavior explicitly shows that the activity of water strongly depends on its nature (tap water or seawater). Therefore, it may be concluded that the diffusion kinetics of water molecules in the PMMA is controlled by the species contained in water.

Longer immersion period, beyond 19 months, generates almost no weight gain (Fig. 6). This seems to show that, under the current aging conditions, only water molecules are concerned with diffusion in PMMA. The displacement of a water molecule in the intersites of this polymer is strongly slowed down by the elements contained in this solvent. This can be explained by the fact that water diffuses into the polymer and enters into the unoccupied intermolecular sites, which leads to the absorption of a large quantity of water. This behavior, which is observed during the first five-month immersion period, can be explained by the nature of the species contained in water. In addition to the fact that most elements in water consist essentially of hydrogen $\left(\mathrm{H}^{+}\right)$and hydroxide $\left(\mathrm{OH}^{-}\right)$ions, seawater also contains a high proportion $(>50 \%)$ of sodium ions $\left(\mathrm{Na}^{+}\right)$and $(>30 \%)$ of chlorine ions $\left(\mathrm{Cl}^{-}\right)$. These two ions appear to have a decisive effect on the weight gain of PMMA. Indeed, these elements tend to slow down the activity of water within the PMMA, which leads to a drop in the flow rate of water molecules inside this polymer. In fact, these molecules penetrate into the macromolecular networks, and this leads to the weakening, or even the breaking, of the secondary bonds between the chains that are responsible for the polymer cohesion. By destroying the secondary bonds of the polymer, water decreases the mechanical cohesion and increases the molecular mobility. It should be noted, however, that the diffusion of water within the PMMA follows the Fickian diffusion pattern below the glass transition temperature, because in this case water plays the role of a plasticizer. This would increase the chain mobility and allow a higher penetration of water, with a maximal percentage of about $2 \%$ of weight increase Grinsted et al. [40]; Nottrott [41]; Mambaye N'Diaye et al. [16]. In this study, the maximum level of drinking water absorbed by PMMA was found corresponding to $1.95 \%$ weight increase; this is comparable to that obtained by the above mentioned authors. These findings suggest that PMMA can absorb up to $2 \%$ of water. After 24 hours of immersion in distilled water, it was found that PMMA can swell by absorbing a small amount of water Mambaye N'Diaye et al. [16]. In another analysis, in 2013, Wayne Nishio Ayrea et al. [42] showed that the amount of absorbed water was around $2 \%$ of weight increase after immersion of the PMMA in water for 30 days. The behavior of the polymer observed by these authors is consistent with the results obtained in this study. Indeed, the absorption kinetics of water molecules turns faster as the solvent gets poorer in dissolved species. The proportions of $2 \%$ and $1.95 \%$, found in this study, correspond to the maximum saturation levels in water molecules (Fig. 6). In domain 1, plasticization is closely related to the nature of water, while in domain 2 , it is independent.

Specimens were first placed in drinking water (tap water) and seawater (Fig. 5) for a certain period of time. Afterwards, they were weighed and tested in uniaxial tension a physical experiment which makes it possible to determine the behavior and to measure the degree of resistance to rupture of a material. The results thus obtained are represented in Figs. 7 and 8. For the legibility of the behavior illustrated in these two figures, the value of the stress at rupture indicated represents the average value of six samples for condition of aging. These figures clearly show that the tensile stress at break and the modulus of elasticity of the PMMA were affected by the amount of absorbed drinking water (tap water) and the quantity of absorbed seawater, respectively (Fig. 6). This behavior is identical to that mentioned by C. Ishiyama et al. [43]. Note 
that the longer the immersion period (36 months), the more significant the degradation is. Indeed, one may observe a premature tensile failure in the PMMA due to the weakening of the intermolecular bonds, which engenders a drop in the cohesion energy of Lennard Jones. Moreover, it is important to note that, regardless of the nature of water, Young's modulus drops sharply during the first months of immersion, and then starts decreasing slowly during the last moments of aging (Figs. 7 and 8).

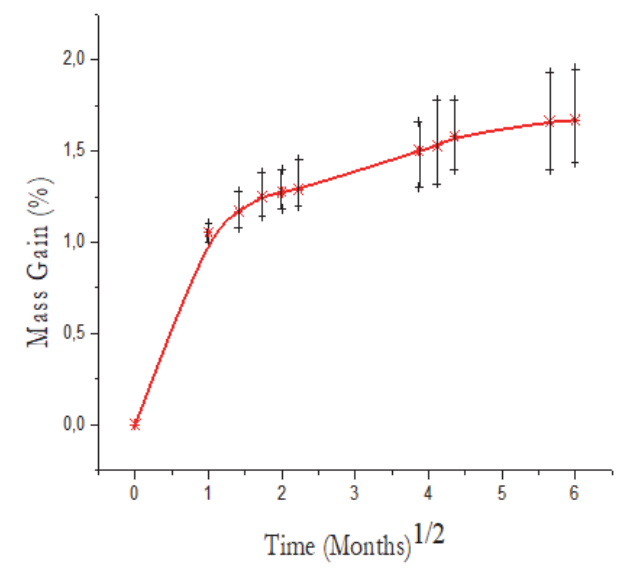

(a)

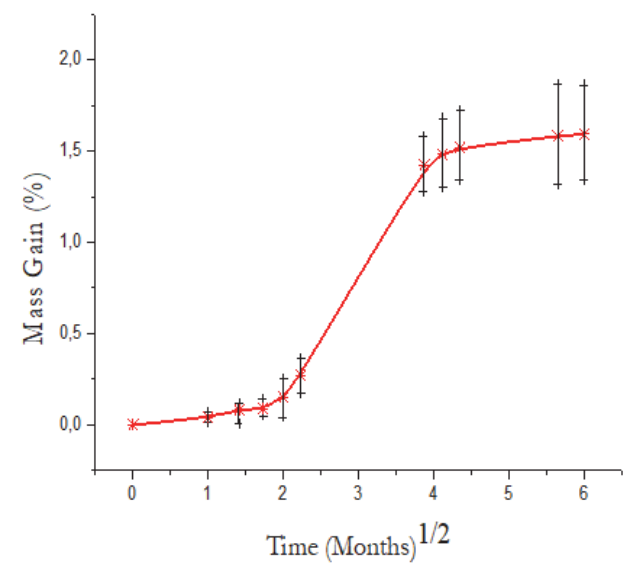

(b)

Figure 5: Effect of immersion time on weight gain (a): Drinking water (tap water), (b) Seawater.

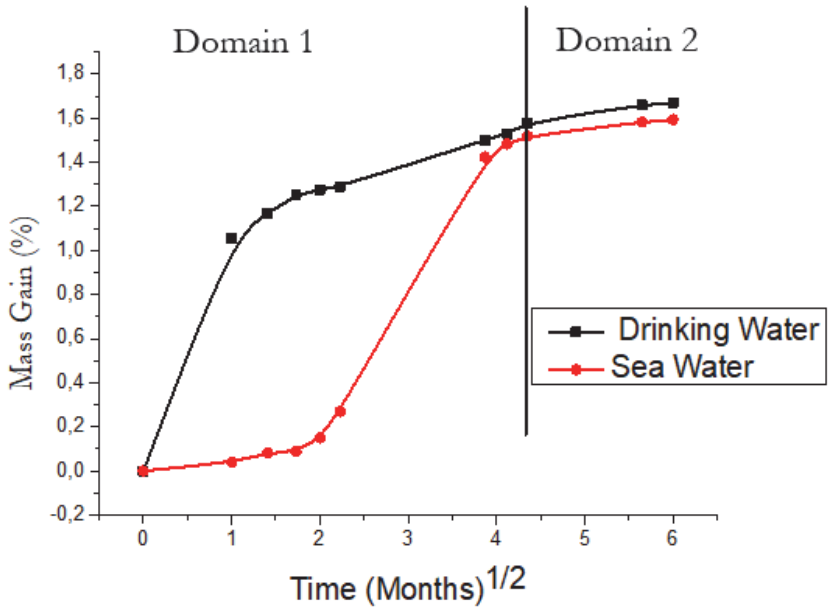

Figure 6: The effects of the nature of solvent and the duration of immersion on the quantity of water absorbed by the PMMA Domain 1: The PMMA mechanical properties are sensitive to the nature of water; Domain 2: The PMMA mechanical properties are insensitive to the nature of water.

This behavior is essentially attributed to the amount of water absorbed by the PMMA. Indeed, because of their small size, the water molecules preferentially diffuse in the intermolecular sites, thus causing a plasticization of the polymer. The plasticization phenomenon causes a relaxation of the polymer chains and an increase in the intermolecular spaces [42]. It is useful to remember that the flow of water in this polymer obeys the Fickian diffusion [42]. Therefore, the penetration depth of the diffusing element is proportional to the square root of time. It is useful to note that the determination of the correlation between the PMMA mechanical properties and Fickian scattering is one of the objectives of this work. This justifies the variation of Young's modulus and the weight gain as a function of the square root of time that is used in this study.

On the other hand, the degradation of PMMA resistance to aging, as a result of the variation in the mechanical characteristics like the tensile strength, strain at break and modulus of elasticity, can be explained by the fact that the water molecules could be attracted by the hydrophilic groups by destroying the hydrogen bonds or van der Waals bonds in the macromolecular network, which can lead to an increase in the distance between the PMMA chains, in addition to a 
significant plasticization in comparison with that generated by the flow of seawater into the PMMA (Fig. 7 ). It is worth noting that this plasticization is responsible for the non-linearity of stress and strain observed during the first five-month period of immersion of the polymer in drinking water (Fig. 8). The increase in the strain at break, in comparison with that obtained in dry PMMA during this first aging period, is characteristic of this non-linear behavior. Consequently, this immersion time leads to a transformation of the initially viscoelastic behavior (dry PMMA) into viscoplastic (hydrated PMMA). It is noted that, beyond that period, the longer the immersion duration, the less important the deformations are (Fig. 9). The mechanical behavior observed in this case tends to become linear and brittle again. After 36 months of aging, the PMMA exhibits a perfectly linear behavior.

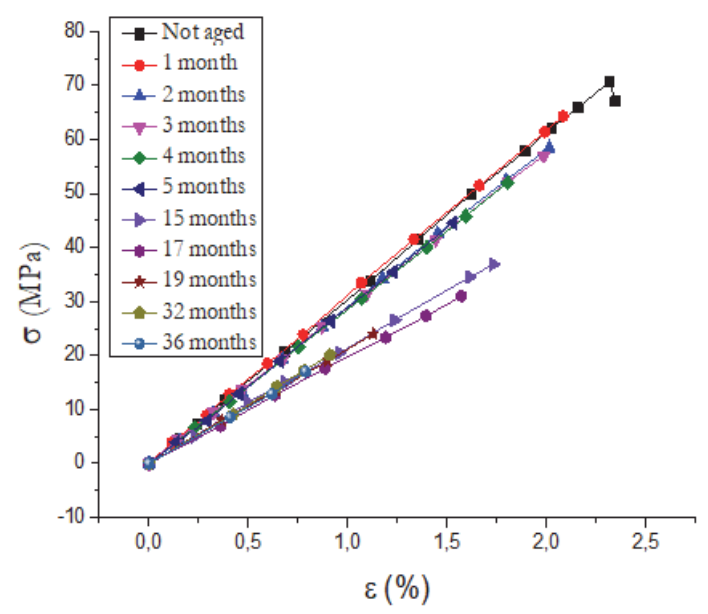

(a)

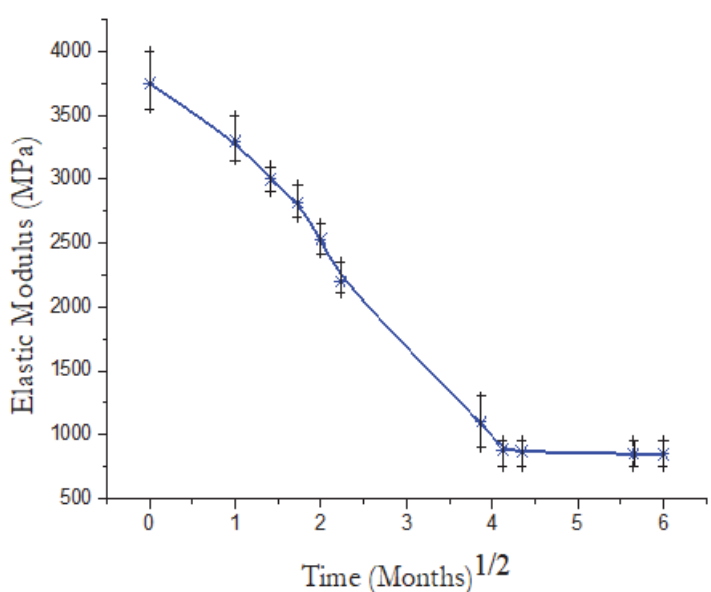

(b)

Figure 7: Effect of immersion time in seawater on the mechanical properties of PMMA for (a) The stress at break, (b) The modulus of elasticity.

For the same duration, and under the same aging conditions, the strain at break observed in samples aged in drinking water (tap water) is much larger than that noted in samples placed in seawater (Fig. 9), which seems to explain the decline in the viscoelastic behavior of PMMA. This behavior is consistent with that observed by Schen et al. [10] and Hamouda et al. [44]. The quantity of drinking water $(1.30 \%)$ absorbed by the PMMA during the first five months of aging is larger than that observed, during the same period, in the case of PMMA immersed in seawater $(0.27 \%)$. The close examination of these results shows that aging in drinking water (tap water) leads to greater plasticization. Therefore, one may conclude that this process is responsible for the transformation of the initially linear viscoelastic behavior into the nonlinear and more ductile viscoplastic of the polymer, as shown in Fig. 9a. In the case of aging in seawater, during the same period, the fragile behavior of PMMA is preserved. Compared with aging in sea water, the low values of tensile strength observed are characteristic of this PMMA behavior (Fig. 9a). In fact, a five-month time period of aging in drinking water (tap water) and in sea water respectively generates a degradation in tensile strength of PMMA from $69 \mathrm{MPa}$ to $27 \mathrm{MPa}$ and from 69 $\mathrm{MPa}$ to $44 \mathrm{MPa}$ (fig. 9a).

During the last five months of aging, the amount of water absorbed is independent of the nature of solvent; it corresponds to the average percentages of $1.58 \%$ in drinking water and $1.55 \%$ in sea water, respectively, as shown in Fig. 6. This clearly indicates that during the last seventeen (17) months of immersion, the plastification is very insensitive to the nature of water used. The degradation rate of the tensile strength of PMMA is approximately $69 \%$ in seawater and $71 \%$ in drinking water (tap water). Moreover, its Young's modulus does not depend on the nature of the aging water; it was found equal to about $77 \%$ and $78 \%$ in seawater and drinking water (tap water), respectively (Figs. 9b and 10). These results are closely related to the amount of water absorbed by the PMMA. Compared to other studies [10, 44], it can be stated that the change in the PMMA behavior (fragile-ductile-fragile) with the nature of aging water and the amount of absorbed water, observed in this study, constitute the originality of this work.

Compared to immersion in seawater, when PMMA is in fresh water (tap water), its modulus of elasticity degrades more rapidly (Fig. 10) during the first five months. The effect of the aging medium disappears after a 19-month period, which represents the saturation phase of this polymer in water. This can certainly be attributed to the amount of water absorbed during the aging period. 
The results obtained in this study clearly suggest that during the first fifteen (15) months of immersion, the degradation kinetics of the mechanical properties (tensile strength and modulus of elasticity) largely depend on the nature of water used; whereas during the last months, it is practically independent.

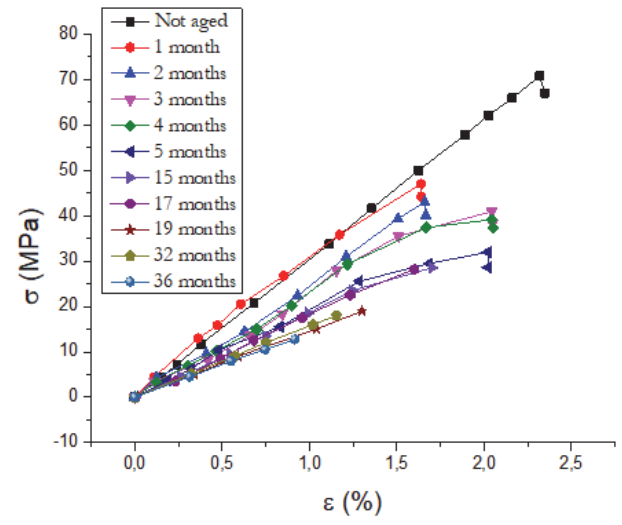

(a)

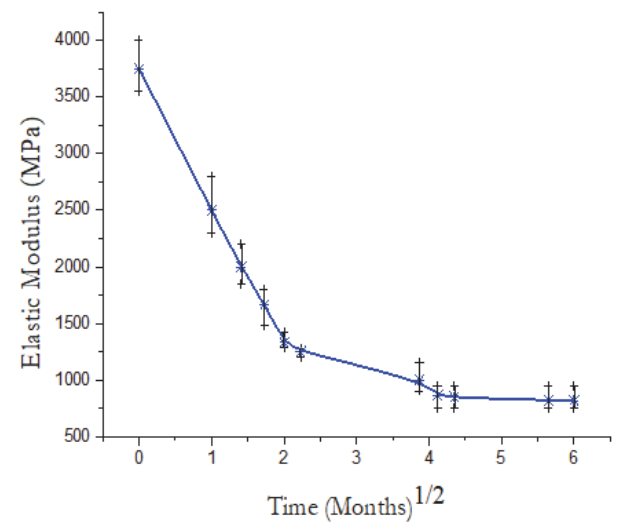

(b)

Figure 8: Effect of immersion time in drinking water (tap water) on the mechanical properties of PMMA: (a) Stress at break, (b) Modulus of elasticity.

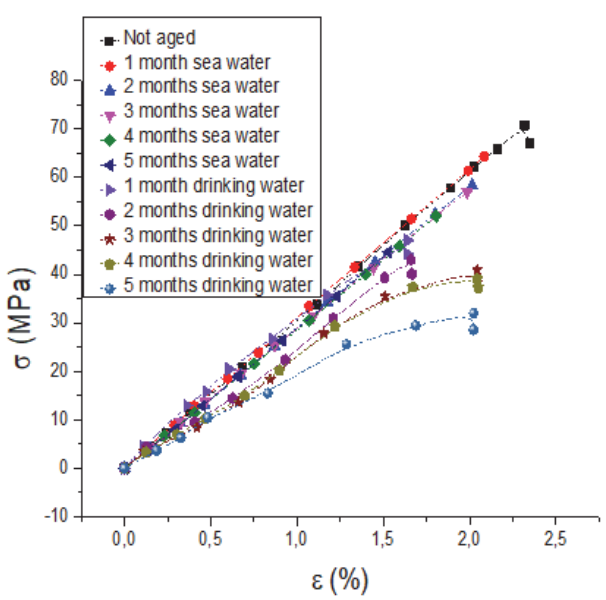

(a)

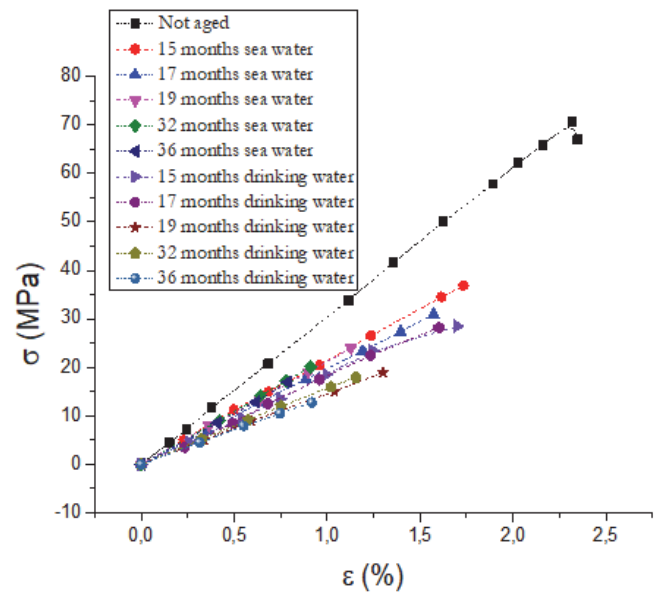

(b)

Figure 9: Comparative analysis of the effect of the nature of aging medium on the mechanical behavior of PMMA: (a) First five months of immersion, (b) Last five months of immersion.

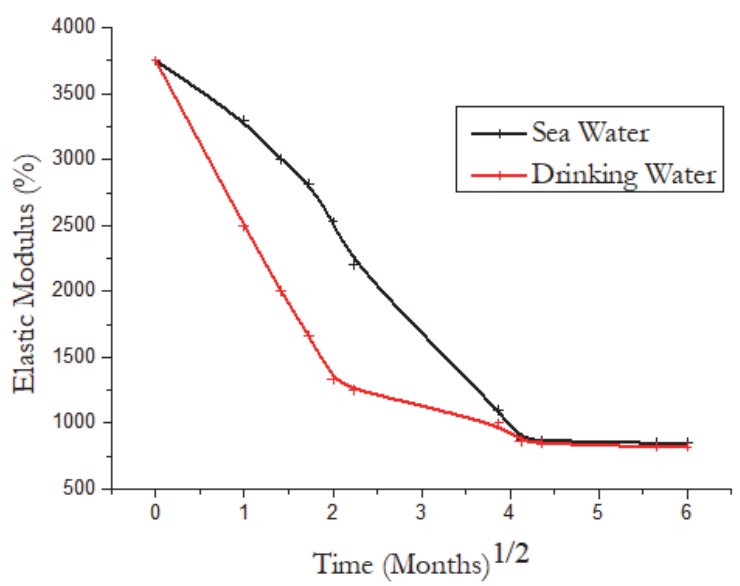

Figure 10: Comparative analysis of Young's modulus of PMMA aged in seawater and in drinking water (tap water). 
This study shows that the amount of water absorbed by the PMMA is independent of the nature of the solvent used; this means that it is also independent of the species contained in this solvent. Only the water absorption kinetics (diffusion) is strongly influenced by these species. This is one of the originalities of this work. To the best of our knowledge, no study has highlighted such a phenomenon. This behavior could mean that no mechanism of irreversible degradation (breaking of chemical bonds, hydrolysis, etc.) has occurred in the PMMA during the absorption phase, either in drinking water (tap water) or in seawater. The plasticizing effect appears to be the main mechanism responsible for the degradation of resistance to aging, which is attributed to the deterioration of the mechanical properties of PMMA after immersion in water. The reversibility of water absorption mechanism (hydration) can only be highlighted through a close examination of moisture desorption (dehydration) in PMMA. This study is in progress.

\section{EXPOSURE TO SOLAR (UV) AND ARTIFICIAL (UV) LAMP RADIATIONS}

$\mathrm{E}$ xposure of the polymer to solar (UV) and artificial (UV) lamp radiations was performed in accordance with the commissioning conditions of the industrial photobioreactor system shown in Fig. 1. To do this, each side of the PMMA specimens was exposed to solar (UV) and artificial (UV) lamp radiations for a period ranging from one (01) to thirty-six (36) months. They were then tested in uniaxial tension, as shown in Figs. 11 and 12. These figures clearly indicate that a continuous exposure of 36 months to artificial (UV) lamp radiations leads to a drop in tensile strength at break, and a decrease in both the strain at break and the elastic modulus of the polymer.

It should be noted, however, that, compared with solar (UV) radiations, exposure of the polymer to artificial (UV) lamp radiations engenders a significant degradation of its stress at break (Figs. 11a, 12a) and its Young's modulus as well (Figs. $11 \mathrm{~b}, 12 \mathrm{~b})$. The deterioration of the polymer mechanical properties is essentially assigned to the absorption of photons. These are potentially aggressive electromagnetic radiations that possess energies corresponding to those of certain chemical bonds. The absorption of photons can cause breaks in molecular chains, thus releasing free radicals and reducing the molecular weight of polymers. This should inevitably lead to degradation of the tensile strength at break, and deterioration of the strain at break, after a cumulative aging of 12 months, with a lower Young's modulus [31, 45-48].

The results obtained in this study show that the artificial (UV) lamp radiations has a more significant effect on the degradation of the polymer mechanical properties. Note that after a cumulative aging of thirty-six months, the solar (UV) radiation does not seem to affect the linear viscoelastic behavior of the polymethyl methacrylate (Fig. 11).

This behavior remains unchanged with regard to the exposure duration. This behavior is observed after an artificial (UV) lamp irradiation time of 3 to 12 months. A too long artificial (UV) lamp irradiation (36 months) leads not only to a considerable drop in tensile strength and Young's modulus, but also to a greater strain at break than that observed in nonirradiated PMMA (Fig. 12a). In fact, it was noted that the tensile strength dropped by about half (Fig. 12a) but the strain at break increased. This clearly indicates that a 36-month cumulative aging seems to lead to a change in the mechanical behavior of PMMA from viscoelastic to viscoplastic. The observed nonlinear behavior is indicative of this transformation. Understanding this change in behavior, which is a topical result, is required for the purpose of comprehending the degradation mechanisms involved in the aging resistance of PMMA irradiated with UV light. This is one of the objectives of this work.

Fig. 13 summarizes the comparative analysis results of the effects of exposure of polymethyl methacrylate to solar (UV) radiations and artificial lamp radiations on its modulus of elasticity (Fig. 13a) and tensile strength (Fig. 13b).

It is clearly illustrated in Fig. 13a that regardless of the duration of aging, in comparison with exposure to solar (UV) radiations, the artificial (UV) lamp radiations causes a significant degradation of the PMMA elastic modulus which drops sharply during the first six (06) months of irradiation, then starts decreasing slowly during the following six months (06); the degradation of this physical parameter is considerably slowed down during the last twenty-four (24) months of aging. It should be noted that the same behavior was observed in the case of PMMA exposed to solar (UV) radiations.

The behavior of the polymer illustrated in Fig. 13b may be better interpreted by referring to Fig. 14 which shows separately the effect of this exposure during the first nine months (Fig. 14a) and during the last twenty-seven months (Fig. $14 \mathrm{~b}$ ) of the exposure period. These figures suggest that the artificial (UV) lamp radiation leads to a slightly higher degradation of tensile strength and to lower strain at break. The initial linear viscoelastic behavior of PMMA remained unchanged during the first twelve months of aging of the polymer exposed to artificial (UV) lamp and solar (UV) radiations (Fig. 14a). After thirty-six months of artificial (UV) lamp radiation, a non-linear behavior was observed (Fig. 14b) with a higher strain at break. It should be noted that this non-linearity in behavior was not observed in the case of PMMA exposed to solar (UV) radiation, for the same period of exposure of 36 months. In addition, a 36-month cumulative aging after exposure of each side of the specimen to artificial (UV) lamp radiation, separately, resulted in a 
$57 \%$ degradation of tensile strength, $10 \%$ increase in the strain at break, and $62 \%$ drop in Young's modulus. For the same duration, exposure of PMMA to solar (UV) radiation leads to a 50\% drop in the stress at break and a 30\% reduction in the strain at break, with a 47\% drop in Young's modulus.

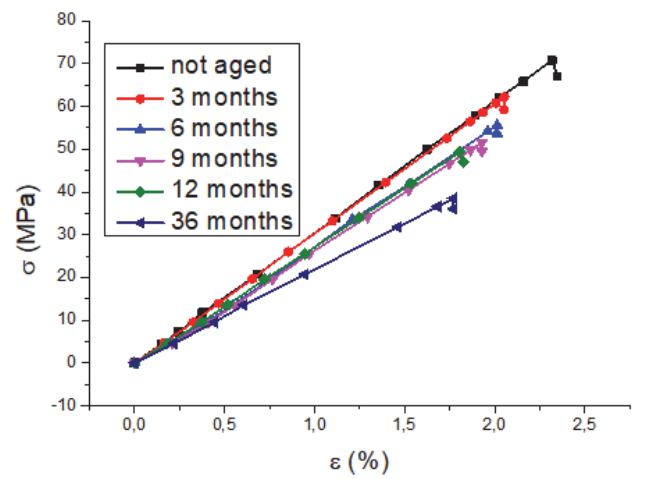

(a)

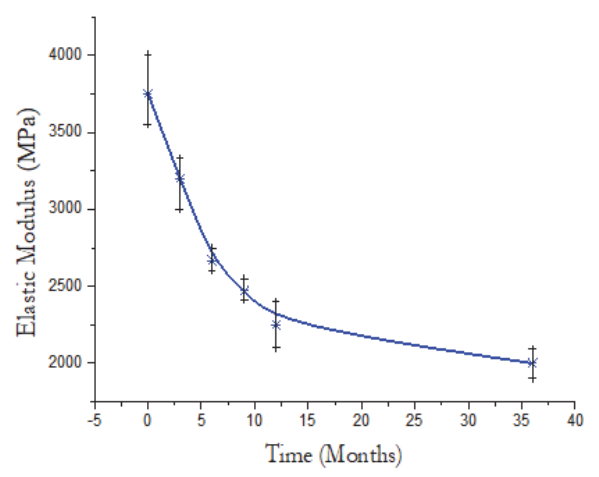

(b)

Figure 11: Effect of the duration of exposure to solar (UV) radiations on the mechanical properties of PMMA: (a) Stress at break, (b) Modulus of elasticity.

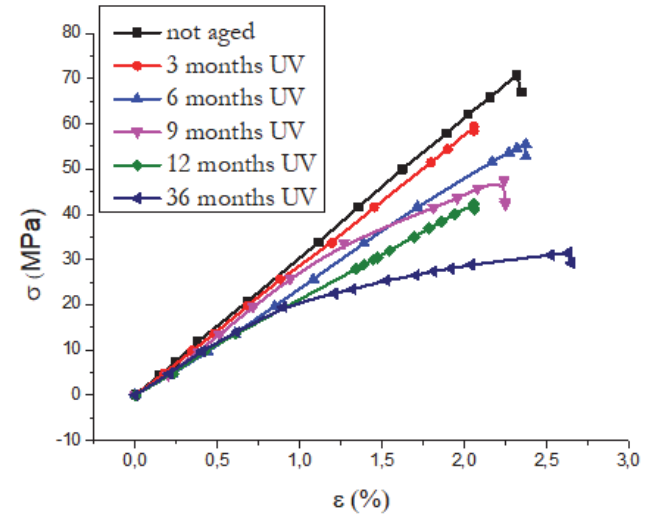

(a)

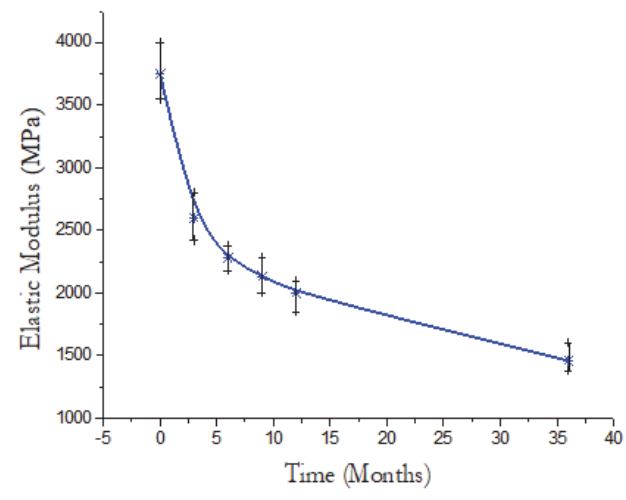

(b)

Figure 12: Effect of the duration of exposure to artificial (UV) lamp radiations on the mechanical properties of PMMA: (a) Stress at break, (b) Modulus of elasticity.

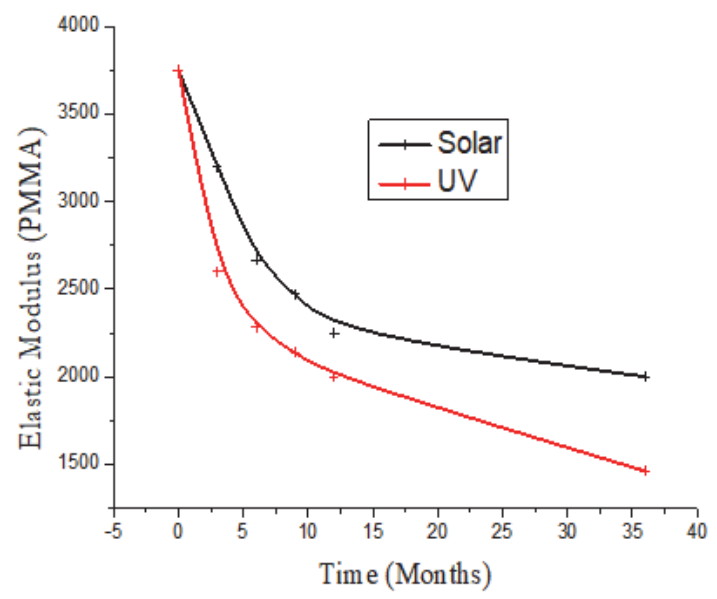

(a)

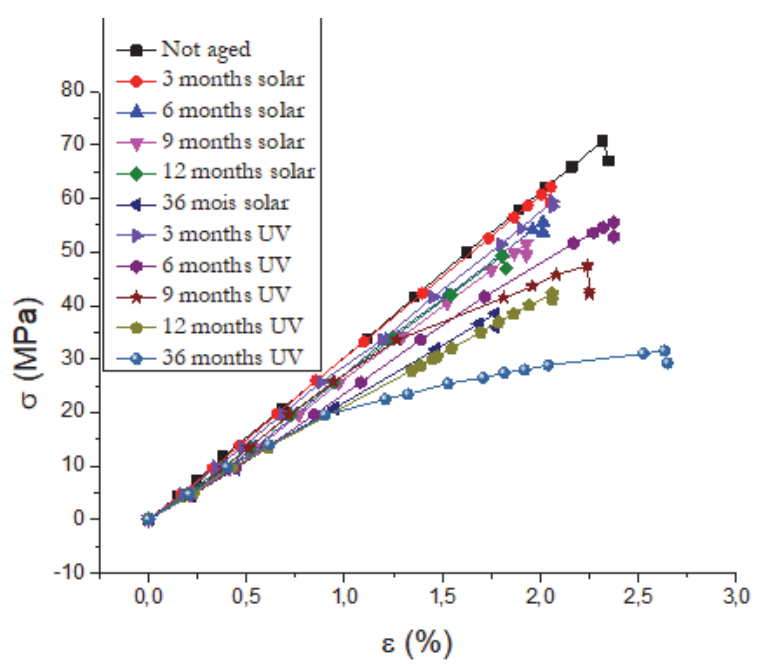

(b)

Figure 13: Comparing the effects of exposure time of PMMA to solar (UV) radiations and artificial (UV) lamp radiations on its mechanical properties: (a) Modulus of elasticity; (b) Stress at break. 


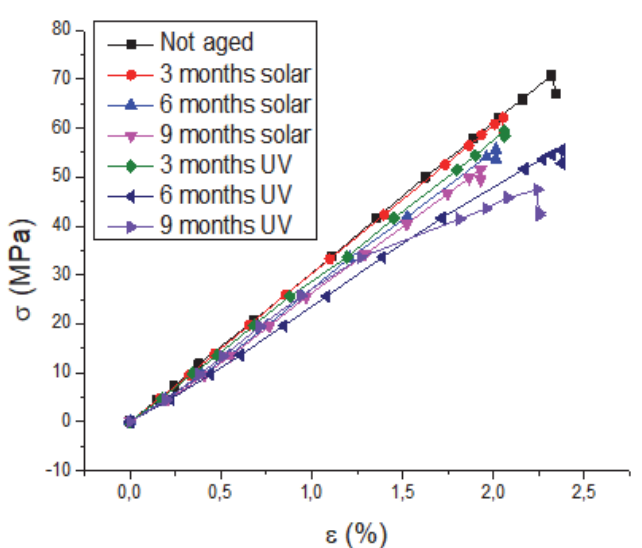

(a)

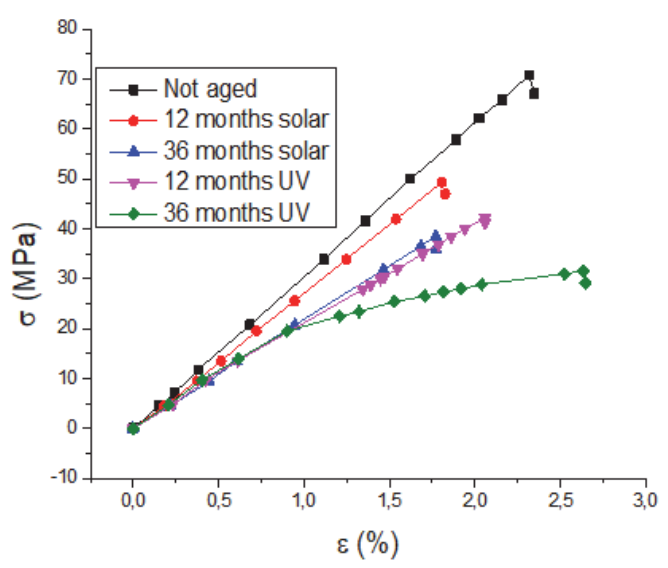

(b)

Figure 14: Comparative analysis of the effects of solar (UV) and artificial (UV) lamp radiations on the mechanical properties of PMMA: (a) Exposure duration: first 9 months; (b) Exposure duration: last 27 months.

\section{CONCLUSION}

$\mathrm{T}$ he analysis of the experimental results obtained in this study, jointly with those reported in the literature, makes it possible to draw the following conclusions:

Aging in water: The amount of water (weight gain) absorbed by the PMMA is closely related to the immersion time in both types of water (tap water and seawater). After a cumulative aging of thirty-six months, the average contents reached for seawater and tap water were $1.51 \%$ and $1.58 \%$, respectively. The maximum values of these quantities correspond to the values of $1.87 \%$ and $1.95 \%$, which are in fairly good agreement with those reported in the literature $(2 \%)$. After twenty months of PMMA hydration, the amount of water absorbed hardly changed with the increase in aging time;

In the first five months of aging, the kinetics of water diffusion in PMMA is closely linked to the nature of the immersion medium. It is greatly slowed down by the species contained in the water;

After a nineteen months immersion time, and regardless of the nature of water, hydration reached a saturation point, beyond which the absorbed water content no longer evolves;

During the first months of immersion (less than 19 months), the diffusion kinetics of water molecules in PMMA was found to depend on the species contained in the solvent used. Their presence considerably slows down the flow rate of water molecules inside the polymer. This rate turned out to be greater in drinking water (tap water) but slower in seawater. In the latter case, the diffusion was delayed and the water molecules took a longer time to reach the maximum amount of water absorbed by the PMMA, after which the polymer reaches a state of saturation in water molecules, after a cumulative aging of 19 months. Beyond this period, the amount of absorbed water becomes independent of the type of solvent used. Only the diffusion kinetics of water molecules within the PMMA depends on the nature of the solvent.

On the other hand, the absorption of water leads to a degradation of aging resistance in terms of reduction of stiffness, tensile strength, and elongation at break of the polymethyl methacrylate (PMMA). During the first five months of immersion in drinking water (tap water), the PMMA changes from the initial linear viscoelastic behavior to the non-linear viscoplastic behavior. Beyond this period, the polymer exhibits a reversible behavior. The PMMA becomes viscoelastic again with a lower tensile strength. Moreover, after nineteen months of immersion, the nature of water has practically no influence on the aging resistance of PMMA. In this case, for the same aging time in drinking water (tap water) and in seawater, the attenuated values of tensile strength and elastic modulus are comparable. This could mean that during the absorption phase, whether in drinking water (tap water) or seawater, no mechanism of irreversible degradation occurs in PMMA. After hydration, plastification seems to be the main mechanism responsible for the drop in resistance to aging. In addition, the reversibility of water absorption can only be proven by a moisture desorption analysis of the PMMA.

UV aging: Exposure to solar (UV) and artificial (UV) lamp radiations leads to degradation of stiffness, tensile strength and strain at break of the polymer. An increase in irradiation time causes a drop in the aging resistance of the PMMA. Compared with exposure to solar (UV) radiation, and for the same duration of aging, artificial (UV) lamp radiation causes 
a greater degradation of mechanical characteristics. The breaking of the macromolecular chain is responsible for the deterioration of PMMA properties;

For longer ultraviolet radiation exposure times (beyond thirty-six months), the linear mechanical behavior of the nonirradiated PMMA changes to a non-linear behavior, with greater deformations as compared to the non-irradiated polymer;

The modulus of Young of the PMMA drops sharply during the first six months of exposure to artificial (UV) lamp radiation then starts decreasing slowly during the following six months. It is important to precise that the degradation of this physical parameter is significantly slowed down during the last twenty-four months of aging. A similar behavior is observed during exposure to solar (UV) radiation but with lower values, regardless of the aging time.

\section{REFERENCES}

[1] Kowalonek, J., Kaczmarek, H., Kurzawa, M. (2016). Effect of UV-irradiation on fluorescence of poly (methyl methacrylate) films with photosensitive organic compounds, Journal of Photochemistry and Photobiology A: Chemistry. 319-320, pp.18-24. DOI: 10.1016/j.jphotochem.2015.12.017

[2] Münker, T.J.A.G., Van de Vijfeijken, S.E.C.M., Mulder, C.S., Vespasiano, V., Becking, A.G., Kleverlaan, C.J., and al. (2018). Effects of sterilization on the mechanical properties of poly(methyl methacrylate) based personalized medical devices, Journal of the Mecchanical Behavior of Biomedical Materials. 81, pp.168-172.

DOI: 10.1016/j.jmbbm.2018.01.033.

[3] Manjunatha, H.C. (2017). A study of gamma attenuation parameters in poly methyl methacrylate and Kapton, Journal of Radiation Physics and Chemistry. 137, pp. 254-259. DOI: 10.1016/j.radphyschem.2016.01.024

[4] Zhong, Z.W., Wang, Z.F., Zirajutheen, B.M.P.( 2005). Chemical mechanical polishing of polycarbonate and poly methyl methacrylate substrates, Journal of Microelectronic Engineering. 81, pp. 117-124.

DOI: 10.1016/j.mee.2005.04.005.

[5] Bussi, Y., Golan, S., Dosoretz, CG., Eisen, MS. (2018). Synthesis, characterization and performance of polystyrene/PMMA blend membranes for potential water treatment, Journal of Desalination. 431, pp.35-46. DOI: $10.1016 /$ j.desal.2017.12.024.

[6] Ali, U., Karim, K.J.B.A., Buang, N.A. (2015). A review of the properties and applications of poly (methyl methacrylate) (PMMA), Journal of Polymer Reviews. 55, pp.678-705. DOI.org/10.1080/15583724.2015.1031377.

[7] Wenhua, Y., Zeyu, X., Yuming, Y., Jun, Y., Xiaodan, L., Huiqin, W., Shuang, W., Yufang, X., Yunong, Y. (2019). Aging behavior and lifetime prediction of PMMA under tensile stress and liquid scintillator conditions, Journal: Advanced Industrial and Engineering Polymer Research. DOI: 10.1016/j.aiepr.2019.04.002.

[8] Bokoi, Y., Ishiyama, C., Shimojo, M., Shiraishi, Y., Higo, Y. (2000). Effects of sorbed water on crack propagation in poly(methyl methacrylate) under static tensile stress, Journal of Materials Science. 35, pp.5001-5011.

DOI: https://doi.org/10.1023/A:1004803030131

[9] Ehsan, M., Reid, B., Hung, J.S. (2014). The effect of moisture exposure on scratch resistance of PMMA, Journal of Tribology International. 69, pp.46-55. DOI: 10.1016/j.triboint.2013.08.

[10] Shen, J., Chen, C., Sauer, J. (1985). Effects of sorbed water on properties of low and high molecular weight PMMA: 1. Deformation and fracture behaviour, Journal of Polymer. 26, pp.511-518. DOI: 10.1016/0032-3861(85)90150-8.

[11] Miller, D.C., Carloni, J.D., Johnson, D.K., Pankow, J.W., Gjersing, E.L., et al. (20.13). An investigation of the changes in poly (methyl methacrylate) specimens after exposure to ultra-violet light, heat, and humidity, Solar Energy, Journal of Materials and Solar Cells. 111, pp.165-180.

[12] Fu, Y., Hsiao, S., Hu, C., Lee, K., Lai, J. (2008). Prediction of long-term physical aging of poly(methyl methacrylate) membranes for gas separation, Journal of Desalination. 234, pp.51-57. DOI: 10.1016/j.desal.2007.09.069.

[13] Cheng, Q., Jiang, C., Zhang, J., Yang, Z., Zhu, Z., Jiang, H. (2016). Effect of thermal aging on the scratch behavior of poly (methyl methacrylate), Journal of Tribology International. 101: 110-114. DOI: 10.1016/j.triboint.2016.04.013

[14] Thominette, F., Verdu, J. (1996). Effect of a tensile stress on the radiolytic degradation of poly (methyl methacrylate), Journal of Polymer. 37, pp.1323-1327. DOI: 10.1016/0032-3861(96)81128-1

[15] Monsores, K. G. C., da Silva, A. O., de Sant'Ana Oliveira, S., Rodrigues, J. G. P., Pondé Weber, R. (2019). Influence of ultraviolet radiation on polymethylmethacrylate (PMMA), Journal of Materials Research and Technology, 8, pp. 3713-3718. DOI: 10.1016/j.jmrt.2019.06.023.

[16] N’Diaye, M., Pascaretti-Grizon, F., Massin, P., Baslé, M. F., Chappard, D. (2012). Water Absorption of Poly (methyl methacrylate) Measured by Vertical Interference Microscopy, GEROM Groupe Etudes Remodelage Osseux et 
bioMatériaux-LHEA, IRIS-IBS Institut de Biologie en Santé, LUNAM Université, CHU d'Angers, 49933 Angers Cedex, France, Chirurgie Orthopédique et Traumatologie, Hôpital Bichat, 75018 Paris, France, (pubs.acs.org/Langmuir). DOI: 10.1021/la302260a.

[17] Myles, P., Murray., Laura, S., Bruckman., and Roger, H, French. (2012). Photodegradation in a stress and response framework: poly (methyl methacrylate) for solar mirrors and lens, Journal of Photonics for Energy. 2. DOI: $10.1117 / 1$.JPE.2.022004.

[18] Yousif, E., Haddad, R. (2013). Photodegradation and photostabilization of polymers, especially polystyrene, Journal of review, SpringerPlus 2. 1, 398. DOI: 10.1186/2193-1801-2-398.

[19] Ghasemi-Kahrizsangi, A., Shariatpanahi, H., Neshati, J., Akbarinezhad, E. (2015). Degradation of modified carbon black/epoxy nanocomposite coatings under ultraviolet exposure, Journal of Applied Surface Science. 353, pp. 530539. DOI: $10.1016 /$ j.apsusc.2015.06.029

[20] Namouchi, F., Smaoui, H., Fourati, N., Zerrouki, C., H. Guermazi, H., Bonnet, JJ. (2009). Investigation on electrical properties of thermally aged PMMA by combined use of FTIR and impedance spectroscopies, Journal of Alloys and Compounds. 469, pp.197-202. DOI: 10.1016/j.jallcom.2008.01.148

[21] Gonzales, O.D., Nicassio, A., Eliasson, V. (2016). Evaluation of the Effect of Water Content on the Stress Optical Coefficient in PMMA, Journal of Polymer testing. 50, pp.119-124. DOI: 10.1016/j.polymertesting.2016.01.004.

[22] Minhyuk, Y., Namchul, J., Changyong, Y., Sangmin J. (2011). Nanomechanical thermal analysis of the effects of physical aging on glass transitions in PS/PMMA blend and PS-PMMA diblockcopolymers, Journal of Polymer, 18 (52): 4136-4140 DOI: 10.1016/j.polymer.2011.06.051.

[23] Šaraca, T., Devauxb, J., Quiévyc, N., Gusarova, A., Konstantinovića, MJ. (2017). The correlation between elongation at break and thermal decomposition of aged EPDM cable polymer, Journal of Radiation Physics and Chemistry. 132 , pp.8-12. DOI: 10.1016/j.radphyschem.2016.10.017.

[24] Vesel Opens, A., Mozetic, M. (2012). Surface modification and ageing of PMMA polymer by oxygen plasma treatment, Journal of vacuum. 6 (86), pp.634-637. DOI: 10.1016/j.vacuum.2011.07.005.

[25] Suzhu, Y., Shu Pei, N., Zhenfeng, W., Chu Long T., Yong Chear, S. (2017). Thermal bonding of thermoplastic elastomer film to PMMA for microfluidic applications, Journal of Surface and Coatings Technology. 320, pp.437-440. DOI: $10.1016 /$ j.surfcoat.2016.11.102.

[26] Jing, Z., Yanyang, Y., Yu L., Liang, Z., Hao, W., Guolin S. (2017). Microencapsulated phase change materials with TiO2-doped PMMA shell for thermal energy storage and UV-shielding, Journal of Solar Energy Materials and Solar Cells. 168, pp.62-68. DOI: 10.1016/j.solmat.2017.04.014.

[27] Merdas, I., Tcharkhtchi, A., Thominette, F., Verdu, J., Dean, K., Cook, W. (2002). Water absorption by uncrosslinked polymers, networks and IPNs having medium to high polarity, Journal of Polymer. 43, pp. 4619-4625. DOI: 10.1016/S0032-3861(02)00267-7.

[28] Serrano-Aroca, Á., Llorens-Gámez, Mar (2017). Dynamic mechanical analysis and water vapour sorption of highly porous poly(methylmethacrylate), Journal of Polymer. 125, pp. 58-65. DOI: 10.1016/j.polymer.2017.07.075.

[29] Miller, D., John, F. Mandell, Daniel, D., Samborsky., B., Hernandez-Sanchezand, A., Todd Griffith, D. (2012). Performance of composite materials subjected to salt water environments, AIAA SDM Wind Energy Session. DOI: $10.2514 / 6.2012-1575$.

[30] Imaizumi, R., Furuta, M., Okamura, H., Matsumoto, A. (2017). UV and y_ray resistance of poly(Nmethylmaleimide_alt-isobutene) and poly(diisopropyl fumarate) as transparent polymer films, Journal of Physics and Chemistry. 138, pp.22-28. DOI: 10.1016/j.radphyschem.2017.04.018.

[31] Senatova, S.I., Senatov, F.S., Kuznetsov, D.V., Stepashkin, A.A., Issi, J.P. (2016). Effect of UV-radiation on structure and properties of PP nanocomposites, Journal of Alloys and Compounds. 707, pp.304-309.

DOI: $10.1016 /$ j.jallcom.2016.11.170.

[32] Lu, T., Solis-Ramos, E., Yun-Bo Yi., Kumosa, M. (2016). Synergistic environmental degradation of glass reinforced polymer composites, Journal of Polymer Degradation and Stability. 131, pp.1-8. DOI: $10.1016 /$ j.polymdegradstab.2016.06.025.

[33] Lu, T., Solis-Ramos, E., Yi., Y., Kumosa, M. (2018). UV degradation model for polymers and polymer matrix composites, Journal of Polymer Degradation and Stability. 154, pp. 203-210.

DOI: $10.1016 /$ j.polymdegradstab.2018.06.004.

[34] Lu, T., Solis-Ramos, E., Yi, Y., Kumosa, M. (2017). Particle removal mechanisms in synergistic aging of polymers and glass reinforced polymer composites under combined UV and water, Journal of Composites Science and Technology. 153, pp.273-281. DOI: 10.1016/j.compscitech.2017.10.028.

[35] Wypych, G. (2011). Handbook of UV Degradation and Stabilization, Toronto. 
[36] Mounier, X. (2017). Molecular dynamics in complex polymer systems: from anisotropy to confinement effects. University de Rouen.

[37] Hanafi, Y. (2017). Study of the degradation of polyethersulfone/polyvinylpyrrolidone membranes by sodium hypochlorite. Rennes doctoral school in matter,molecules and materials (Le Mans) in partnership with the University of Brittany Loire (ComuE) and the Rennes Institute of Chemical Sciences (laboratory). 1.

[38] Ahmed Haseg, N. (2018). Contribution to the study of the relaxation and ageing in amorphous polymers.

[39] Géraldine (2018). Rapp, Multi-scale analysis of the thermo-oxidative aging of a mixture of polyethylene reticles. Clermont Auvergne.

[40] Grinsted, R.A., Clark, L., Koenig, J.L. (1992). Study of cyclic sorption-desorption into poly (methyl methacrylate) rods using NMR imaging, Journal of Macromolecules. 25 (4), pp.1235-1241. DOI:.org/10.1021/ma00030a006.

[41] Nottrott, M. (2010). Acrylic bone cements, journal of Acta Orthopaedica. 81 (S341), pp.1-27. DOI: $10.3109 / 17453674.2010 .487929$.

[42] Ayrean, N., Denyerb, S. P., Evansa, S. L. (2014). Ageing and moisture uptake in polymethyl methacrylate (PMMA) bone cements Wayne, Journal of the mechanical behavior of biomedical materials. 32, pp.76-88.

DOI: 10.1016/j.jmbbm.2013.12.010.

[43] Ishiyama, C., Higo, Y. (2002). Effects of humidity on Young's modulus in poly (methylmethacrylate), Journal of Polymer Science Part B. 40, pp.460-465 DOI: 10.1002/polb.10107.

[44] Hamouda, A. (2002). The influence of humidity on the deformation and fracture behaviour of PMMA, Journal of Materials Processing Technology. 124, pp.238-243. DOI: 10.1016/S0924-0136(02)00096-1.

[45] Yan, L., Chouw, N., Jayaraman, K. (2015). Effect of UV and water spraying on the mechanical properties of flax fabric reinforced polymer composites used for civil engineering applications, Journal of Materials and Design. 71, pp.17-25. DOI: 10.1016/j.matdes.2015.01.003.

[46] Kahlen, S., Jerabek, M., Wallner, G.M., Lang, R.W. (2009). Characterization of physical and chemical aging of polymeric solar materials by mechanical testing, Journal of Polymer Testing. 29, pp.72-81.

DOI: $10.1016 /$ j.polymertesting.2009.09.007.

[47] Cordelle, A., Drissi-Habti, M., Aaron Forster., Joannie Chin. (2013). Effects of UV irradiation on the mechanical properties of polymer composite materials, Journal of Review of composites and advanced materials, Lavoisier. 23 (2), pp.295-309.

[48] Colom, X., García, T., Suñol, J.J., Saurina, J., Carrasco, F. (2001). Properties of PMMA artificially aged, Journal of Non-Crystalline Solids. (1-3) 287, pp.308-312. DOI: 10.1016/S0022-3093(01)00571-3. 